\title{
Inhibitory effect of atorvastatin on the cell growth of cardiac myxomas via the PTEN and PHLPP2 phosphatase signaling pathway
}

\author{
XING-LI WU $^{1 *}$, DING-YOU YANG ${ }^{2 *}$, DUAN-JUN TAN ${ }^{3}$, HENG-CHEN YAO $^{4}$, WENHUI CHAI $^{5}$ and LI PENG ${ }^{1}$ \\ ${ }^{1}$ Institute of Geriatric Cardiology, Chinese PLA General Hospital, Beijing; ${ }^{2}$ Department of Traditional Chinese Medicine, \\ The First Affiliated Hospital of Chinese PLA General Hospital, Beijing, P.R. China; ${ }^{3}$ Cancer Prevention and \\ Population Sciences, Roswell Park Cancer Institute, Buffalo, NY, USA; ${ }^{2}$ Department of Cardiology, \\ Liaocheng City Hospital, Shandong; ${ }^{5}$ Department of Geriatric Cardiology, \\ Changji City Hospital, Xinjiang, P.R. China
}

Received February 7, 2013; Accepted May 4, 2013

DOI: 10.3892/or.2013.2501

\begin{abstract}
Insulin-like growth factor 1 (IGF-1) is a molecule with strong proliferative effects, and statins have been reported to exhibit antitumor effects based on clinical and experimental studies. However, their effects on cardiac myxoma (CM) cells and the underlying signaling mechanism(s) are largely unknown. Therefore, we investigated whether the protein/lipid phosphatases and tensin homolog deleted on chromosome ten (PTEN) and pleckstrin homology domain leucine-rich repeat phosphatase 1 and 2 (PHLPP1 and 2) are involved in the proliferative effect of IGF-1 on CM cells and the pharmacological impact of atorvastatin. The activity of PTEN and PHLPPs was determined using specific substrate $\mathrm{diC}_{16} \mathrm{PIP}_{3}$ and pNPP. We found that IGF-1 enhanced CM cell proliferation and inhibited both PTEN and PHLPP2 activity in a concentration- and time-dependent manner. Atorvastatin acted counter to IGF-1 and reversed the above effects mediated by IGF-1. Both IGF-1 and atorvastatin did not affect the activity of PHLPP1 and the protein expression of the three phosphatases. The results suggest that IGF-1 may exert its proliferative effects by negatively regulating the PTEN/ PHLPP2 signaling pathway in CM cells, and atorvastatin may
\end{abstract}

Correspondence to: Professor Xing-Li Wu, Institute of Geriatric, Cardiology, Chinese PLA General Hospital, Fuxinglu 28 , Beijing 100853, P.R. China

E-mail:wx1301@yahoo.com

*Contributed equally

Abbreviations: Ator, atorvastatin; CMs, cardiac myxomas; IGF-1, insulin-like growth factor-1; PTEN, phosphatases and tensin homolog deleted on chromosome ten; PHLPP1 and 2, pleckstrin homology domain leucine-rich repeat phosphatase 1 and 2

Key words: atorvastatin, cardiac myxoma cells, IGF-1, PTEN, PHLPP be a potential drug for the treatment of CM by enhancing the activity of PTEN and PHLPP2.

\section{Introduction}

Cardiac myxomas (CMs) are mostly sporadic and only a few are familial myxomas that are mainly referred to as Carney complex $(1,2)$. Clinical features and long-term outcome such as recurrence, heart failure, sudden death and embolisms have been reported $(3,4)$. However, due to the limited understanding of the molecular mechanisms leading to the development and progression of CM, no target drug is available. Surgical excision of the tumor is still the only current treatment option, however this approach has increased risk of death and may be followed by recurrences, myocardial infarction and stroke (5). Therefore, there is an urgent need to elucidate the molecular mechanisms of CM and to develop new targeting chemotherapy agents.

To date, dozens of molecules and molecular markers of sporadic cardiac my xoma have been studied which include interleukin-6, interleukin-8 and growth-related oncogenes (5-10). Insulin-like growth factor-1 (IGF-1) is a well-known survival factor for both normal and malignant cells in many tissues, including the prostate and the vascular system (11-13). Elevated IGF-1 levels have been found in certain patients with Carney complex, and it has been recommended as being suggestive of or possibly associated with the disorder (14-16). However, the role of IGF-1 in sporadic myxoma and the related signaling pathways are largely unknown.

Studies using cancer cell lines revealed that the signal transduction cascade underlying IGF-1 involved phosphoinositide 3-kinase/protein kinase-B (PI3K/Akts) (17-20). The Akts are indirectly downregulated from upstream by the lipid and protein double phosphatase and tensin homolog deleted on chromosome ten (PTEN) (21-25) and inactivated by $\mathrm{PH}$ domain leucine-rich repeat phosphatase 1 and 2 (PHLPP1 and 2) through dephosphorylating its hydrophobic motif directly from downstream. We previously demonstrated that IGF-1 increased the over-proliferation of vascular smooth 
muscle cells (VSMCs) by increasing phosphorylation of Akt and repressing PTEN activation. Transgene experiments found that the functional loss of PTEN or PHLPP induced the activation of Akt, a critical component of the survival and oncogenic function of IGF-1, and led to the development of various types of cancer $(18,26-29)$. IGF-1 has been regarded as a potential target for tumors and over-proliferating disorders such as atherosclerosis. Statins, as cholesterol lowering drugs, have also exhibited cancer-retardant efficacy in several in vitro and in vivo models and epidemiological studies (30-39). However, the study of whether the PTEN/PHLPP signaling pathway is involved in the pleiotropic effect of statins is still obscure.

The aim of the present study was to elucidate whether PTEN and PHLPPs are expressed in CM cells constitutively or following stimulation by IGF-1, and to clarify the effect and molecular mechanism of statins.

\section{Materials and methods}

Reagents. The antibodies against PHLPP1 and PHLPP2 were obtained from Bethyl Laboratories Inc. (Montgomery, TX, USA). Anti-PTEN was from Cell Signaling (Beverly, MA, USA). Atorvastatin was from Pfizer (New York, NY, USA).

Culture of CM cells. The culture of CM cells was performed as previously described (8). Myxoma tissues from a 46-yearold patient with sporadic cardiac myxoma were obtained during surgical operation at our hospital. The patient provided informed consent, and the study protocol was approved by the China PLA General Hospital Medical Ethics Committee. The cardiac myxoma cells were extracted ex vivo by enzymatic digestion with collagenase and were maintained, after differential trypsinization and morphological confirmation, in Dulbecco's modified Eagle's medium. Before stimulation experiments, the medium was replaced with serum-free DMEM for $24 \mathrm{~h}$ and then replaced with fresh medium plus the indicated agents for different times. For examination of the expression of the signaling proteins, cells were treated for $24 \mathrm{~h}$ without control or with IGF-1 $(100 \mu \mathrm{g} / \mathrm{l})$ or with atorvastatin $(10 \mu \mathrm{M})$, or pretreated for $10 \mathrm{~min}$ with atorvastatin $(10 \mu \mathrm{M})$ and then with IGF-1 (100 $\mu \mathrm{g} / \mathrm{l})$ for $24 \mathrm{~h}$. To assess the effect of IGF-1 and atorvastatin on the activity of PTEN and PHLPPs, the cells were treated for $0,1 / 12,1 / 6,1,6,24$ $\mathrm{h}$ with atorvastatin $(0,0.1,1,5,10,100 \mu \mathrm{M})$ or IGF-1 $(0,0.1$, $1,5,10,100 \mu \mathrm{g} / \mathrm{l})$, or pretreated for $10 \mathrm{~min}$ with atorvastatin $(10 \mu \mathrm{M})$ and thereafter with IGF-1 (100 $\mu \mathrm{g} / \mathrm{l})$ for $10 \mathrm{~min}$. CM cells were seeded in triplicate at a density of $2.5 \times 10^{5}$ cells/ $\mathrm{ml}$ on 24-well plates. After incubation for the indicated time, the medium was removed and the cells were stored at $-80^{\circ} \mathrm{C}$ until assay.

Proliferation assays. The proliferation assays were performed as previously described (8). Cells were seeded into plastic wells and allowed to grow for $48 \mathrm{~h}$ in culture medium with $10 \%$ FBS. After $24 \mathrm{~h}$ in serum-free medium, the cells were treated with atorvastatin $(0,0.1,1,5,10,100 \mu \mathrm{M})$ or IGF-1 $(0,0.1$, $1,5,10,100 \mu \mathrm{g} / \mathrm{l})$ or pretreated for $30 \mathrm{~min}$ with atorvastatin $(10 \mu \mathrm{M})$ followed by stimulation with IGF-1 $(0,0.1,1,5,10$, $100 \mu \mathrm{g} / \mathrm{l})$ for $48 \mathrm{~h}$ under high serum conditions and exposed to DMEM containing $1 \mathrm{mCi}\left[{ }^{3} \mathrm{H}\right]$ thymidin for a further $24 \mathrm{~h}$. The cells were washed, harvested and processed for counting in a liquid scintillation counter.

Western blot analysis. The cellular lysates were prepared as previously described $(26,27)$. Lysates containing equal protein were separated by SDS-PAGE and transferred to polyvinyldifluoride membranes. For anti-PHLPP1, antiPHLPP2 and anti-PTEN blotting, membranes were incubated for $2 \mathrm{~h}$ with the indicated antibodies. Blots were then washed and incubated with horseradish peroxidase-linked anti-rabbit secondary antibody for $3 \mathrm{~h}$. Densitometric analysis was performed with ImageJ analysis software.

Immunoprecipitation. Whole cell lysates were incubated for $1 \mathrm{~h}$ with $1 \mu \mathrm{g}$ of PTEN, PHLPP1 or PHLPP 2 antibody and then with protein $\mathrm{A} / \mathrm{G}$ Plus-agarose for $24 \mathrm{~h}$ at $4^{\circ} \mathrm{C}(28,40)$.

PTEN lipid phosphatase assay. The immunoprecipitated PTEN was added to reaction buffer (100 $\mathrm{mM}$ Tris $\mathrm{pH} 8.0$, $10 \mathrm{mM}$ DTT, 0.01\% Brij 35, $1 \mathrm{~g} / 1 \mathrm{BSA}, 1 \mathrm{mM}$ EDTA, $25 \mu \mathrm{M}$ $\mathrm{diC}_{16} \mathrm{PIP}_{3}$ ) for $30 \mathrm{~min}$ at $37^{\circ} \mathrm{C}$, then terminated by the addition of Biomol Green reagent (Biomol). The amount of phosphate in the supernatant was determined by reading the absorbance of the samples at $620 \mathrm{~nm}$ following incubation for $30 \mathrm{~min}$. Phosphate concentrations were estimated by comparison to $\mathrm{KH}_{2} \mathrm{PO}_{4}$ standards diluted $(0-1000 \mathrm{pM})(11,27)$.

Assay of PHLPP activity. Briefly, PHLPP1 and PHLPP2 were immunoprecipitated, and their activities were measured using pNPP as a substrate. Dephosphorylation of pNPP was measured by continuously monitoring the change in absorbance at $405 \mathrm{nM}(28,40)$.

Statistical analysis. Values are expressed as means \pm SD from at least 3 independent experiments. The significance of differences between groups was determined using one-way ANOVA statistical analysis. The threshold for significance was set at a p-value $<0.05$. Statistical analysis was performed using SPSS 19.0 statistical software.

\section{Results}

Effect of IGF-1 and atorvastatin on the proliferation of CM cells. IGF-1 caused a 2.0- to 4.9-fold increase in $\left[{ }^{3} \mathrm{H}\right]$ thymidin incorporation in a concentration-dependent mode (5-100 $\mu \mathrm{g} / \mathrm{l}$, $\mathrm{p}<0.05)$, which was abolished by atorvastatin. Atorvastatin decreased the constitutive proliferation of CM cells dosedependently $(5-100 \mu \mathrm{M}, \mathrm{p}<0.05)$ by $49-77 \%$ (Fig. 1).

Effect of IGF-1 and atorvastatin on the expression of PTEN and PHLPPs in CM cells. IGF-1, atorvastatin, and IGF-1 plus atorvastatin did not affect the protein expression of PTEN, PHLPP1 and PHLPP2 after stimulated for $24 \mathrm{~h}$ (Fig. 2).

Effect of IGF-1 on the activity of PTEN and PHLPPS in CM cells. IGF-1 deceased both PTEN and PHLPP2 but not PHLPP1 activity by $22-44 \%$ and $18-69 \%$ separately $(\mathrm{p}<0.01)$ in a time-dependent mode, with a maximum depressive effect noted at $5 \mathrm{~min}$ and lasting at least for $24 \mathrm{~h}$ (Fig. 3). IGF-1 inhibited both PTEN and PHLPP2 but not PHLPP1 activity by 


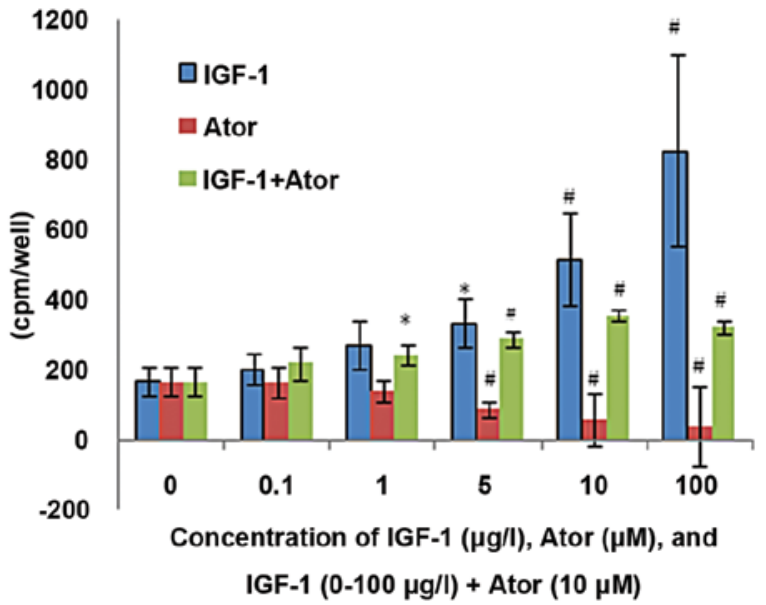

Figure 1. IGF-1 and atorvastatin affected the proliferation of CM cells. After $24 \mathrm{~h}$ in serum-free medium, the cells were treated with atorvastatin (Ator) $(10 \mu \mathrm{M})$ or IGF-1 $(100 \mu \mathrm{g} / \mathrm{l})$ or pretreated for $30 \mathrm{~min}$ with atorvastatin $(10 \mu \mathrm{M})$ and thereafter with IGF-1 (100 $\mu \mathrm{g} / \mathrm{l})$ for $48 \mathrm{~h}$, and then exposed to DMEM containing $1 \mathrm{mCi}\left[{ }^{3} \mathrm{H}\right]$ thymidin for a further $24 \mathrm{~h}$. IGF-1 caused a 2.0 - to 4.9-fold increase in $\left[{ }^{3} \mathrm{H}\right]$ thymidin incorporation in a concentration dependent mode. Atorvastatin decreased DNA synthesis by $49-77 \%$ concentrationdependently and inhibited the proliferation of CM cells induced by IGF-1. The measurements were performed in triplicate, and data are presented as means $\pm \mathrm{SD}(\mathrm{n}=6)$. Significance vs. control: ${ }^{*} \mathrm{p}<0.05,{ }^{*} \mathrm{p}<0.01$.

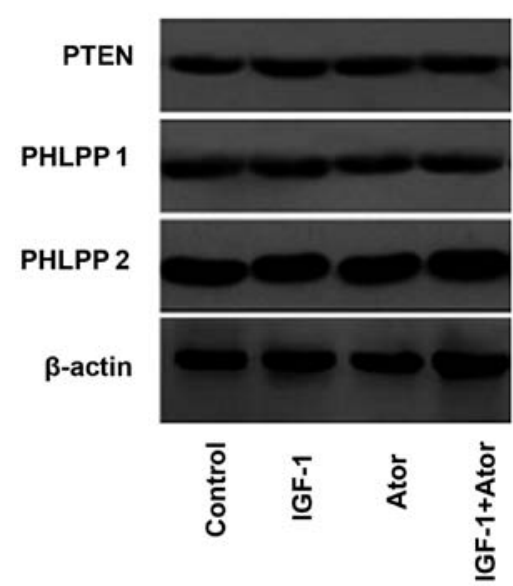

Figure 2. IGF-1 and atorvastatin did not affect the expression of PTEN, PHLPP1 and PHLPP2. Before the stimulation experiments, medium was replaced with serum-free DMEM for $24 \mathrm{~h}$ and then replaced with fresh medium plus the indicated agents for different periods of time. For examination of the expression of the signaling proteins, cells were treated for $24 \mathrm{~h}$ without control or with IGF-1 (100 $\mu \mathrm{g} / \mathrm{l})$ or with atorvastatin (Ator) $(10 \mu \mathrm{M})$, or pretreated for $10 \mathrm{~min}$ with atorvastatin $(10 \mu \mathrm{M})$ and then with IGF-1 $(100 \mu \mathrm{g} / \mathrm{l})$ for $24 \mathrm{~h}$. Lysates were separated by SDS-PAGE and transferred to polyvinyldifluoride membranes. Membranes were incubated for $2 \mathrm{~h}$ with the indicated antibodies and then with horseradish peroxidase-linked anti-rabbit secondary antibody for $3 \mathrm{~h}$.

$14-54 \%$ and $14-70 \%$ separately in a concentration-dependent mode $(5-100 \mu \mathrm{g} / 1, \mathrm{p}<0.01)$ (Fig. 4). These findings suggest that IGF-1 signaling was via the PTEN and PHLPP2 pathway in CM cells.

Effect of atorvastatin on the activity of PTEN and PHLPPs in $C M$ cells. Atorvastatin increased the constitutive phosphatase activity of PTEN and PHLPP2 but not PHLPP1 to 1.83- to
aPTEN घPHLPP1 $₫$ PHLPP2

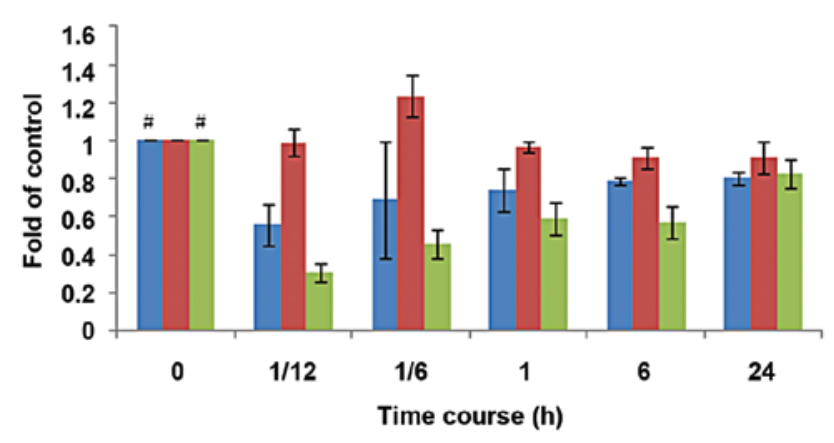

Figure 3. Time-course effect of IGF-1 on PTEN, PHLPP1 and PHLPP2 phosphatase activity. To determine whether PTEN, PHLPP1 and PHLPP2 or both are involved in IGF-1 signaling in CMs, cell lysates were immunoprecipitated with relative antibodies, and the phosphatase activity was determined. Serum-starved cells were treated with or without IGF-1 (100 $\mu \mathrm{g} / \mathrm{l})$ for various periods of time ( $0-24 \mathrm{~h})$. Cells were lysed, immunoprecipitated, and assayed for phosphatase activity. The measurements were performed in triplicate $(\mathrm{n}=6)$. Significance vs. control: ${ }^{*} \mathrm{p}<0.01$.

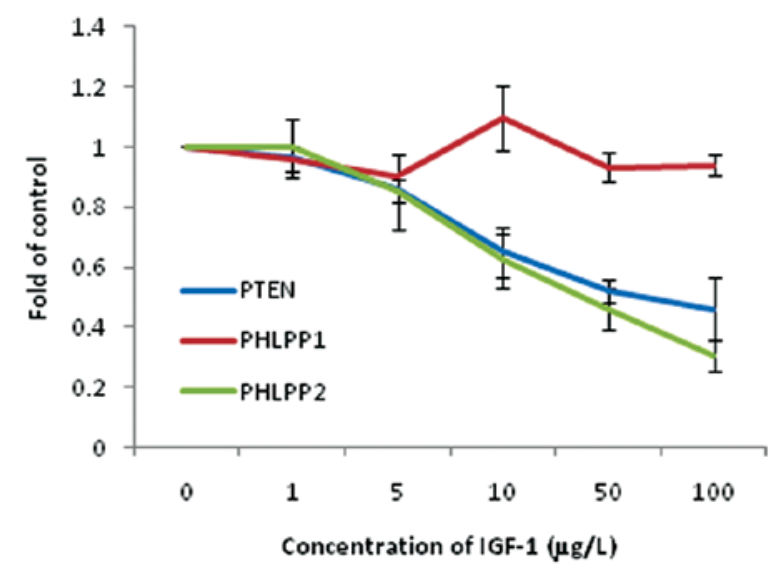

Figure 4. Dose-dependent effect of IGF-1 on PTEN, PHLPP1 and PHLPP2 phosphatase activity. Serum-starved cells were treated with or without IGF-1 at various concentrations $(0-100 \mu \mathrm{g} / \mathrm{l})$ for $5 \mathrm{~min}$, immunoprecipitated with antibodies against PTEN, PHLPP1 and PHLPP2, and assayed for their activity in vitro. The measurements were performed in triplicate $(n=6)$. Significance vs. control: ${ }^{*} \mathrm{p}<0.05,{ }^{,} \mathrm{p}<0.01$.

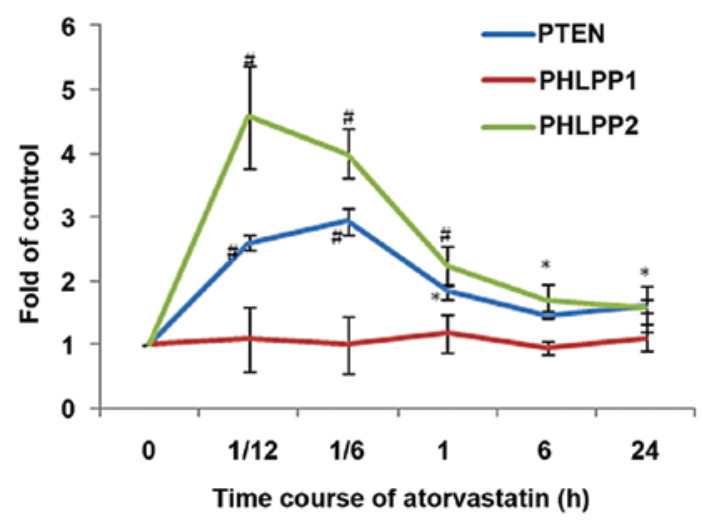

Figure 5. Time-course effect of atorvastatin on PTEN, PHLPP1 and PHLPP2 phosphatase activity. Serum-starved cells were treated with or without atorvastatin $(10 \mu \mathrm{M})$ for various periods of time $(0-24 \mathrm{~h})$. Cells were lysed, immunoprecipitated, and assayed for phosphatase activity. The measurements were performed in triplicate $(n=6)$. Significance vs. control: ${ }^{*} \mathrm{p}<0.05$, ${ }^{\#} \mathrm{p}<0.01$. 


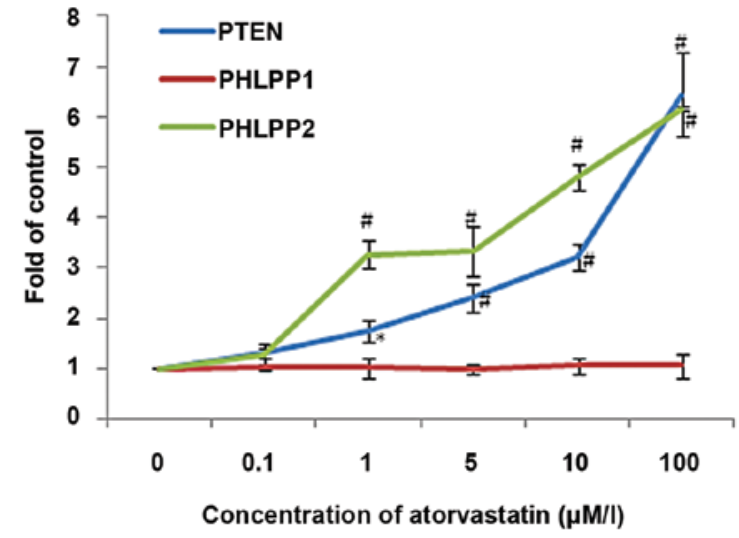

Figure 6. Dose-dependent effect of atorvastatin on PTEN, PHLPP1 and PHLPP2 activity. To determine the effect of atorvastatin on PTEN, PHLPP1 and PHLPP2 activity in CMs, serum-starved cells were treated with or without atorvastatin at various concentrations $(0-100 \mu \mathrm{M})$ for $5 \mathrm{~min}$, immunoprecipitated with antibodies against PTEN, PHLPP1 and PHLPP2, and assayed for their activity in vitro. The measurements were performed in triplicate ( $\mathrm{n}=6)$. Significance vs. control: ${ }^{*} \mathrm{p}<0.05,{ }^{\sharp} \mathrm{p}<0.01$.

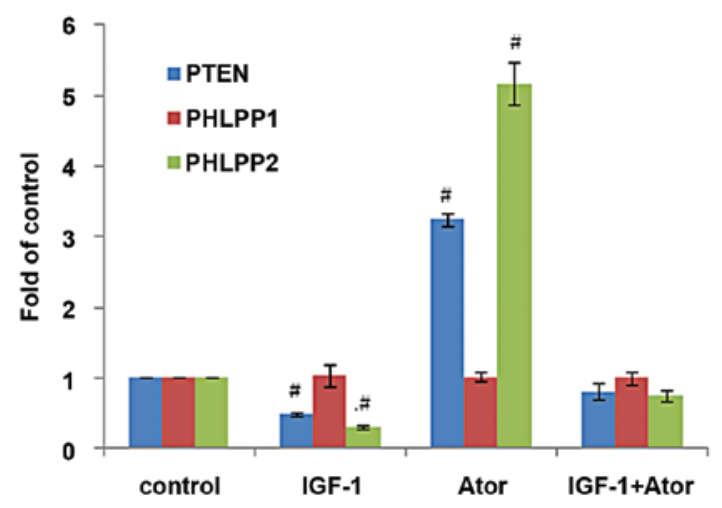

Figure 7. Atorvastatin increased both PTEN and PHLPP2 phosphatase activity inhibited by IGF-1. To assess the effect of atorvastatin on the activity of PTEN and PHLPPs influenced by IGF-1, the cells were treated for $5 \mathrm{~min}$ with atorvastatin (Ator) $(10 \mu \mathrm{M})$, IGF-1 $(100 \mu \mathrm{g} / \mathrm{l})$, or pretreated for $10 \mathrm{~min}$ with atorvastatin $(10 \mu \mathrm{M})$ and thereafter with IGF-1 $(100 \mu \mathrm{g} / \mathrm{l})$ for $5 \mathrm{~min}$ Cells were lysed, immunoprecipitated, and assayed for the PTEN. PHLPP1 and PHLPP2 phosphatase activity as mentioned above. The measurements were performed in triplicate $(n=6)$. Significance vs. control: ${ }^{\#} \mathrm{p}<0.01$.

2.9-fold and 1.7- to 4.57-fold separately $(\mathrm{p}<0.01)$ in a timedependent mode which lasted for 1 and $6 \mathrm{~h}$ separately (Fig. 5). Atorvastatin increased constitutive phosphatase activity of PTEN and PHLPP2 but not PHLPP1 to 1.73- to 6.43-fold and 3.27- to 6.17-fold separately in a concentration-dependent mode (5-100 $\mu \mathrm{M}, \mathrm{p}<0.05)$ (Fig. 6).

Effect of atorvastatin on the activity of PTEN and PHLPPs in $C M$ cells induced by IGF-1. Atorvastatin $(10 \mu \mathrm{M})$ increased PTEN and PHLPP2 phosphatase activity inhibited by IGF-1 $(100 \mu \mathrm{g} / \mathrm{l})$ by 32 and $45 \%$ separately and reversed them nearly to the level of the control (both $\mathrm{p}<0.01$ ) (Fig. 7).

\section{Discussion}

To elucidate the molecular mechanism of CM, a wide spectrum of molecules and molecular markers has been studied, which include higher expression of membrane-associated MUC1 gene, matrix metalloproteinases, vascular endothelial growth factor and its receptors, basic fibroblast growth factor and its receptor, endothelin and its precursor, monocyte chemotactic protein-1, thymidine phosphorylase, transforming growth factor $\beta$, epidermal growth factor, interleukin- 6 , interleukin- 8 and growth-related oncogenes (5-10). It was reasoned that abnormalities in the expression levels of any of these molecules can potentially contribute to cancer pathogenesis, but the signaling pathways are poorly understood and targeting drugs for sporadic cardiac myxoma are unknown.

Recent experiments revealed that PKB/Akt and protein and lipid dual phosphatase PTEN were involved in the survival and proliferation of various cancer cell lines. It was also believed that IGF-1 may play an important role in the carcinogenesis of certain malignancies $(18,26)$, but IGF-1 has rarely been investigated in CM cells.

Previous data from our laboratory and other centers have shown that IGF-1 activated PI3K/Akt. In turn it phosphorylates an array of substrates to regulate cell survival, proliferation, growth, metabolism and motility $(11,27)$. The Akts are indirectly downregulated from upstream by the lipid phosphatase PTEN (21-25), and inactivated by PHLPP directly from downstream. PHLPPs selectively regulate Akt isoforms. PHLPP1 dephosphorylates Akt-2, whereas PHLPP2 dephosphorylates Akt-1. By specifically dephosphorylating the hydrophobic motif, PHLPP1 controls the degree of agonist-evoked signaling by Akt and the cellular levels of PKC. The aberrant regulation of either kinase and phosphatase was noted in many diseases, notably diabetes and cancer (28,40-43).

Recently, Wahdan-Alaswad et al reported that IGF-1 is a critical regulator of prostate tumor cell growth, which is mediated by its ability to suppress bone morphogenetic protein-induced apoptosis and Smad-mediated gene expression through a mechanism dependent on the PI3K, Akt, Raptor and Rictor signaling pathway (17). It has not yet been elucidated whether PTEN and PHLPPs are expressed in CM cells constitutively or following stimulation by IGF-1.

In the present study, we found that IGF-1 increased the proliferation of CM cells to 2.0 to -4.9 times that of the control in a concentration- and time-dependent manner. This was similar to our previous study on VSMCs in which the proliferation was increased significantly by IGF-1 (27). The signal mechanistic study revealed that PTEN, PHLPP1 and PHLPP2 were constitutively expressed in CM cells. Furthermore, IGF-1 stimulation resulted in a significant decrease in PTEN and PHLPP2 activity but not PHLPP1 activity, suggesting that IGF-1 primarily utilizes Akt-1 to transmit its signal in CMs.

For the drug interference study, we selected atorvastatin, since statins have been used for dozens of years for the treatment of cardiovascular diseases and have been reported to be associated with a significant reduction in the risk of cancer and lymphoma (32-39). Research of relative molecular mechanisms have demonstrated that statins inhibited the synthesis of mevalonate or of downstream isoprenoids, decreased the availability of dolichol, impeded the glycosylation of nascent IGF-1 receptors, prevented their transfer to the cell surface, and eventually exerted cancer-retardant efficacy (30-32). Miraglia et al recently reported that long-term treatment of non-small cell lung cancer A549 cells with high concentrations of statins 
increased PTEN expression, enhanced PHLPP2 expression, decreased PHLPP1 expression and inhibited downstream pAkt signaling (32).

In the present study, atorvastatin decreased the DNA synthesis of CMs by $49-77 \%$ concentration-dependently and reversed the proliferative effect of IGF-1. This result was similar to that of Brown et al who reported that lipophilic statins including atorvastatin reduced the migration and colony formation of PC-3 cells in human bone marrow stroma by inhibiting geranylgeranyl pyrophosphate production, reducing the formation and the spread of metastatic prostate colonies (37). An in vivo study using Wistar rats by Parada et al also found that atorvastatin had a clear inhibitory effect on bladder cancer development, probably due to its antioxidant, antiproliferative and anti-inflammatory properties. Regarding protein expression, our findings were not consistent with those of Miraglia et al, who found significant changes in the three proteins following treatment with atorvastatin (32). These discrepancies perhaps due to the different dose and incubation period used.

It is meaningful to point out that in the present study atorvastatin possessed a strong and lasting inhibitory effect on the proliferation of $\mathrm{CM}$ cells even at a concentration $(1 \mu \mathrm{M})$ relevant for lowering cholesterol levels and for preventing cardiovascular disease. In addition, this study demonstrated that atorvastatin not only increased the phosphatase activity of PTEN and PHLPP2 constitutively but also significantly restored their phosphatase activity inhibited by IGF-1, which suggests that atorvastatin may exert its anticancer effect by positive regulation of phosphatase activity as previously reported in pancreatic cancer and prostate cancer cells (41-44).

In conclusion, our study supports the hypothesis that altered phosphatase signaling plays a role in the tumorigenesis of CM, and statins may have chemopreventive effects on CM by regulating the regulator of the Akt pathway. This finding is important for the management of CM, since patients with this disorder often first present at the cardiology department, and statins are widely used in cardiovascular disease prevention by physicians who are familiar with its usage and side effects. This may lead to an easy and affordable strategy for the post-operative treatment of CM, however further evidence from large clinical trials is warranted.

\section{Acknowledgements}

We thank Tianran Wu from Melbourne University in Australia for editing the manuscript.

\section{References}

1. Roschkov S, Rebeyka D, Mah J and Urquhart G: The dangers of cardiac myxomas. Prog Cardiovasc Nurs 22: 27-30, 2007.

2. Wilkes D, McDermott DA and Basson CT: Clinical phenotypes and molecular genetic mechanisms of Carney complex. Lancet Oncol 6: 501-508, 2005.

3. Figueroa-Torres Y, Martínez-Ojeda JA, Franqui-Rivera H, et al: Benign cardiac neoplasms: the experience at the Cardiovascular Center of Puerto Rico and the Caribbean. PR Health Sci J 27: 373-376, 2008

4. Wu X, Yang D, Yang Z, et al: Clinical characteristics and long term post-operative outcome of cardiac myxoma. EXCLI J 11 240-249, 2012
5. Barh D, Kumar A, Chatterjee S and Liloglou T: Molecular features, markers, drug targets, and prospective targeted therapeutics in cardiac myxoma. Curr Cancer Drug Targets 9: 705-716, 2009

6. Chu PH, Jung SM, Yeh TS, et al: MUC1, MUC2 and MUC5AC expressions in cardiac myxoma. Virchows Arch 446: 52-55, 2005.

7. Orlandi A, Ciucci A, Ferlosio A, et al: Increased expression and activity of matrix metalloproteinases characterize embolic cardiac myxomas. Am J Pathol 166: 1619-1628, 2005.

8. Sakamoto H, Sakamaki T, Kanda T, et al: Vascular endothelial growth factor is an autocrine growth factor for cardiac myxoma cells. Circ J 68: 488-493, 2004.

9. Fujisawa H, Koide N, Kono T, et al: Expression of basic fibroblast growth factor and its receptor-1 in cardiac myxoma. J Cardiovasc Surg 43: 589-594, 2002.

10. Amano J, Kono T, Wada Y, et al: Cardiac myxoma: its origin and tumor characteristics. Ann Thorac Cardiovasc Surg 9: 215-221, 2003.

11. Uzoh CC, Holly JMP, Biernacka KM, et al: Insulin-like growth factor-binding protein-2 promotes prostate cancer cell growth via IGF-dependent or -independent mechanisms and reduces the efficacy of docetaxel. Br J Cancer 104: 1587-1593, 2011.

12. Rzucidlo EM: Signaling pathways regulating vascular smooth muscle cell differentiation. Vascular 17 (Suppl 1): S15-S20, 2009.

13. Perks C: The role of insulin-like growth factor binding proteins. Neuroendocrinology 83: 154-160, 2006.

14. Mateus C, Palangié A, Franck N, et al: Heterogeneity of skin manifestations in patients with Carney complex. J Am Acad Dermatol 59: 801-810, 2008.

15. Raff SB, Carney JA, Krugman D, et al: Prolactin secretion abnormalities in patients with the 'syndrome of spotty skin pigmentation, myxomas, endocrine overactivity and schwannomas' (Carney complex). J Pediatr Endocrinol Metab 13: 373-379, 2000 .

16. Kurtkaya-Yapicier O, Scheithauer BW, Carney JA, et al: Pituitary adenoma in Carney complex: an immunohistochemical, ultrastructural, and immunoelectron microscopic study. Ultrastruct Pathol 26: 345-353, 2002.

17. Wahdan-Alaswad RS, Song K, Krebs T, et al: Insulin-like growth factor I suppresses bone morphogenetic protein signaling in prostate cancer cells by activating mTOR signaling. Cancer Res 70: 9106-9117, 2012.

18. Grimberg A: Mechanisms by which IGF-I may promote cancer. Cancer Biol Ther 2: 630-635, 2003.

19. Liu B, Lee KW, Anzo M, et al: Insulin-like growth factorbinding protein-3 inhibition of prostate cancer growth involves suppression of angiogenesis. Oncogene 26: 1811-1819, 2007.

20. Vivanco I and Sawyers CL: The phosphatidylinositol 3-kinase AKT pathway in human cancer. Nat Rev Cancer 2: 489-501, 2002.

21. Waalkes S, Simon P, Hennenlotter J, et al: Altered expression of Akt signaling pathway parameters in prostate needle biopsies derived from benign, adjacent and cancerous tissue. Oncol Rep 23: $1257-1260,2010$

22. Falbo V, Floridia G, Censi F, et al: Three cases of rare salivary gland tumours: a molecular study of TP53, CDKN2A/ARF, RAS, $B R A F, P T E N, M A P K 2$ and EGFR genes. Oncol Rep 26: 3-11, 2011.

23. Tserga A, Michalopoulos NV, Levidou G, et al: Association of aberrant DNA methylation with clinicopathological features in breast cancer. Oncol Rep 27: 1630-1638, 2012.

24. Bouali S, Chrétien AS, Ramacci C, et al: PTEN expression controls cellular response to cetuximab by mediating PI3K/AKT and RAS/RAF/MAPK downstream signaling in KRAS wildtype, hormone refractory prostate cancer cells. Oncol Rep 21: 731-735, 2009.

25. Jang K, Kim M, Seo HS, et al: PTEN sensitizes MDA-MB-468 cells to inhibition of MEK/Erk signaling for the blockade of cell proliferation. Oncol Rep 24: 787-793, 2010.

26. Garcia JA and Danielpour D: Mammalian target of rapamycin inhibition as a therapeutic strategy in the management of urologic malignancies. Mol Cancer Ther 7: 1347-1354, 2008.

27. Wu XL, Yang DY, Yang ZS, et al: Effect of IGF-1 on PI3K/PTEN signal pathway in vascular smooth muscle cell. Zhongguo Ying Yong Sheng Li Xue Za Zhi 20: 259-262, 2004 (In Chinese).

28. Brognard J, Sierecki E, Gao T, et al: PHLPP and a second isoform, PHLPP2, differentially attenuate the amplitude of Akt signaling by regulating distinct Akt isoforms. Mol Cell 25: 917-931, 2007.

29. Gao T, Brognard J and Newton AC: The phosphatase PHLPP controls the cellular levels of protein kinase C. J Biol Chem 283: 6300-6311, 2008. 
30. McCarty MF: Suppression of dolichol synthesis with isoprenoids and statins may potentiate the cancer-retardant efficacy of IGF-I down-regulation. Med Hypotheses 56: 12-16, 2001.

31. Martínez-González J, Viñals M, Vidal F, et al: Mevalonate deprivation impairs IGF-I/insulin signaling in human vascular smooth muscle cells. Atherosclerosis 135: 213-223, 1997.

32. Miraglia E, Högberg J and Stenius U: Statins exhibit anticancer effects through modifications of the pAkt signaling pathway. In J Oncol 40: 867-875, 2012

33. Duncan RE, El-Sohemy A and Archer MC: Statins and cancer development. Cancer Epidemiol Biomarkers Prev 14: 1897-1898, 2005.

34. Bonovas S, Filioussi K, Tsavaris N, et al: Statins and cancer risk: a literature-based meta-analysis and meta-regression analysis of 35 randomized controlled trials. J Clin Oncol 24: 4808-4817, 2006.

35. Chan KK, Oza AM and Siu LL: The statins as anticancer agents Clin Cancer Res 9: 10-19, 2003.

36. Lutski M, Shalev V, Porath A and Chodick G: Continuation with statin therapy and the risk of primary cancer: a population-based study. Prev Chronic Dis 9: E137, 2012.

37. Brown M, Hart C, Tawadros T, et al: The differential effects of statins on the metastatic behaviour of prostate cancer. $\mathrm{Br} \mathrm{J}$ Cancer 106: 1689-1696, 2012.

38. Parada B, Reis F, Pinto A, et al: Chemopreventive efficacy of atorvastatin against nitrosamine-induced rat bladder cancer: antioxidant, anti-proliferative and anti-inflammatory properties. Int J Mol Sci 13: 8482-8499, 2012.
39. Lai SW, Liao KF, Lai HC, et al: Atorvastatin correlates with decreased risk of esophageal cancer: a population-based casecontrol study from Taiwan. Libyan J Med 7: 18830, 2012.

40. Miyamoto S, Purcell NH, Smith JM, et al: PHLPP-1 negatively regulates Akt activity and survival in the heart. Circ Res 107: 476-484, 2010.

41. Nitsche C, Edderkaoui M, Moore RM, et al: The phosphatase PHLPP1 regulates Akt2, promotes pancreatic cancer cell death, and inhibits tumor formation. Gastroenterology 142: 377-387, 2012.

42. Mulholland DJ, Tran LM, Li Y, et al: Cell autonomous role of PTEN in regulating castration-resistant prostate cancer growth. Cancer Cell 19: 792-804, 2011.

43. Lee JK, Edderkaoui M, Truong P, et al: NADPH oxidase promotes pancreatic cancer cell survival via inhibiting JAK2 dephosphorylation by tyrosine phosphatases. Gastroenterology 133: 1637-1648, 2007.

44. Mistafa O, Ghalali A, Kadekar S, et al: Purinergic receptormediated rapid depletion of nuclear phosphorylated Akt depends on pleckstrin homology domain leucine-rich repeat phosphatase, calcineurin, protein phosphatase 2A, and PTEN phosphatases. J Biol Chem 285: 27900-27910, 2010. 